\title{
Role of Plasma Gelsolin and the Vitamin D-binding Protein in Clearing Actin from the Circulation
}

Stuart E. Lind, David B. Smith, Paul A. Janmey, and Thomas P. Stossel

Hematology-Oncology Unit, Massachusetts General Hospital; and Department of Medicine, Harvard Medical School, Boston, Massachusetts 02114

\begin{abstract}
We determined the plasma kinetics of both actin and complexes of actin with the two high affinity actin-binding proteins of plasma, gelsolin, and vitamin D-binding protein (DBP). Actin is cleared rapidly from the plasma by the liver (half-disappearance time, $0.5 \mathrm{~h}$ ). Using radiolabeled actin-binding proteins, we found that actin accelerated the clearance of both plasma gelsolin and the vitamin D-binding protein. In separate experiments we found that DBP-actin complexes were cleared more quickly than gelsolin-actin complexes, at a rate comparable to the clearance of actin from the blood. A low affinity interaction (dissociation constant, $2.9 \times 10^{-4} \mathrm{M}$ ) between actin and fibronectin was found, suggesting that little actin will bind to fibronectin in plasma. We conclude that while plasma gelsolin and DBP may both clear actin from the circulation, DBP appears to play a more important role. By so doing, DBP may conserve the filament-severing activity of plasma gelsolin.
\end{abstract}

\section{Introduction}

Actin is the most abundant protein found in mammalian cells, comprising up to $10-20 \%$ of many nucleated cells and $60 \%$ of the protein of muscle cells (1). Therefore we can surmise that cell death, whether physiologic or pathologic in origin, might cause actin to appear in significant amounts outside of the cell. There it could interact with extracellular proteins, such as two high affinity actin-binding proteins that exist in plasma, plasma gelsolin, also called brevin, or actin depolymerizing factor (25), and the vitamin D-binding protein (DBP), ${ }^{1}$ also called Gc globulin $(6,7)$.

Using DNase-Sepharose, Thorstensson et al. adsorbed a 42,000-D polypeptide from normal serum that cross-reacted with an antiactin antibody (8), suggesting that actin may be found in the blood of healthy subjects. On the other hand, Emerson and colleagues have presented immunochemical evidence that actinDBP complexes can be found in the serum of pregnant women (9) or patients with acute hepatic necrosis (10), but not in the serum of healthy humans. Thus, it is not clear if actin is found in normal serum. Further evidence, albeit indirect, speaking for

Address correspondence to Dr. Lind, Hematology-Oncology Unit, Massachusetts General Hospital, Boston, MA 02114.

Received for publication 10 December 1985 and in revised form 2 May 1986.

1. Abbreviations used in this paper: $\mathrm{DBP}$, vitamin D-binding protein; TC, tyramine-cellobiose.

J. Clin. Invest.

(c) The American Society for Clinical Investigation, Inc.

0021-9738/86/09/0736/07 \$1.00

Volume 78, September 1986, 736-742 the presence of actin in extracellular fluid is found in reports of patients who have antiactin antibodies in their blood $(11,12)$.

Since there is evidence that actin may be released into the extracellular space, we have studied the kinetics of clearance of actin from the circulation. In so doing, it was necessary to examine the effect of actin upon the plasma kinetics of DBP and plasma gelsolin. Although the plasma kinetics of DBP are known (13), such information is not available for plasma gelsolin. It was therefore necessary to establish the kinetics of plasma gelsolin. We then examined the effects of actin upon the clearance of plasma gelsolin and DBP. Finally, we examined the interaction between actin and fibronectin in vitro to clarify fibronectin's role in clearing actin from the circulation.

\section{Methods}

\section{Materials}

Enzymobeads were obtained from Bio-Rad Laboratories, Richmond, CA; ${ }^{125}$ I from New England Nuclear, Boston, MA; Iodogen from the Pierce Chemical Company, Rockford, IL; and chemicals from Sigma Chemical Co., St. Louis, MO. Reagents for preparing the tyraminecellobiose (TC) conjugates were generous gifts of Dr. Ray Pittman, University of California at San Diego, San Diego, California.

\section{Protein preparation}

Plasma gelsolin was isolated from human and rabbit plasma as previously described (14). DBP was isolated from rabbit plasma by the method of Haddad et al. (15) after an initial purification step in which $200 \mathrm{ml}$ of plasma was passed over a 10-ml column of Sepharose 4B conjugated to a monoclonal antigelsolin antibody (16) (3 mg antibody/ml of gel) to remove plasma gelsolin. Fibronectin was purified by the method of Vuento and Vaheri (17) using a gelatin-Sepharose column. The fibronectin was eluted from the column with $1 \mathrm{M}$ arginine, $\mathrm{pH}$ 5.5. Rabbit skeletal muscle actin was purified by the method of Spudich and Watt (18) and stored as G-actin in buffer A ( $2 \mathrm{mM}$ Tris, $0.2 \mathrm{mM} \mathrm{CaCl}, 0.2$ mM ATP, and $0.1 \mathrm{mM}$ mercaptoethanol, $\mathrm{pH}$ 7.6). F-actin was prepared by the addition of $\mathrm{KCl}$ and $\mathrm{Mg}^{2+}$ to final concentrations of $100 \mathrm{mM}$ and $2 \mathrm{mM}$, respectively.

$100-\mu \mathrm{g}$ aliquots of plasma gelsolin, fibronectin, DBP, and actin were labeled with ${ }^{125} \mathrm{I}$ by lactoperoxidase-coated beads (Enzymobeads) following the manufacturer's specifications. Before iodination, actin was dialyzed against buffer $A$ minus mercaptoethanol. After iodination, the reaction mixture was passed over a Sephadex G-25 column equilibrated with a solution containing either $150 \mathrm{mM} \mathrm{NaCl}, 10 \mathrm{mM}$ phosphatebuffered saline, pH 7.4 (PBS), and $1 \mathrm{mg} / \mathrm{ml}$ bovine serum albumin (BSA) (for plasma gelsolin, DBP, and fibronectin) or buffer A with $1 \mathrm{mg} / \mathrm{ml}$ BSA (for actin). The adequacy of this separation was assessed by precipitating the labeled protein $(10 \mu \mathrm{l})$ with $1 \mathrm{ml}$ of ice-cold $10 \%$ TCA in the presence of $50 \mu \mathrm{l}$ of carrier serum. Fractions that were $>90 \%$ TCAprecipitable were used for the experiments described. The radiolabeled proteins were subjected to electrophoresis in 5-15\% polyacrylamide gels in sodium dodecyl sulfate followed by autoradiography. The labeled proteins migrated at the same position as the unlabeled molecules. The specific activities were as follows: radiolabeled fibronectin, 350; gelsolin, 50; DBP, 15; and actin, $2 \mathrm{Ci} / \mathrm{mmol}$, respectively. 
In addition, the ability of radiolabeled gelsolin to nucleate actin filament assembly was determined. Radiolabeled gelsolin was incubated with actin, labeled with $N$-(1-pyrenyl)iodoacetamide (pyrene-actin) by the method of Kouyama and Mihashi (19) in buffer A, as previously described (5), before the addition of $\mathrm{MgCl}_{2}$ and $\mathrm{KCl}$ (final concentrations of 2 and $100 \mathrm{mM}$, respectively). The fluorescence of pyrene-labeled actin increased in solutions containing labeled gelsolin at $95 \%$ of the rate of solutions containing unlabeled gelsolin (Fig. 1), indicating that the labeled gelsolin had retained its function. Previous experiments employing gel filtration chromatography showed that the radiolabeled gelsolin eluted as a single species (20).

Human plasma gelsolin and rabbit skeletal muscle actin were labeled with a TC adduct by the method of Pittman et al. $(21,22)$. In this method the TC adduct is prepared by reductive amination to form a compound that is not hydrolyzed in cells, thus preventing reutilization of the label and indicating the final degradation site of the labeled protein. The adduct was iodinated using the Iodogen method before being added to a crosslinking reagent, cyanuric chloride, which coupled the adduct to the protein. The activated ligand $(46 \mu \mathrm{g}$ ) was added to $330 \mu \mathrm{g}$ of gelsolin or 900 $\mu \mathrm{g}$ of actin and allowed to react for $75 \mathrm{~min}$ at room temperature. The labeled actin (TC-actin) was centrifuged at $35,000 \mathrm{~g}$ for $1 \mathrm{~h}$ at $4^{\circ} \mathrm{C}$, resuspended in PBS, and then dialyzed against PBS for $18 \mathrm{~h}$. The labeled gelsolin (TC-gelsolin) was passed over a Sephadex G-25 column equilibrated with PBS and $1 \mathrm{mg} / \mathrm{ml} \mathrm{BSA}$ and was then dialyzed against PBS for $18 \mathrm{~h}$ before being injected into rabbits.

Efforts were made to remove damaged radiolabeled molecules before the performance of the clearance studies. In some experiments, plasma gelsolin was screened by using one rabbit to remove damaged molecules before their injection into a second rabbit, which was then used to determine the kinetics of the protein. $10 \mu \mathrm{g}$ of radioactive gelsolin was injected into a healthy rabbit. $3 \mathrm{~h}$ later, the rabbit was anesthetized with sodium pentobarbital and bled by cardiac puncture into heparin-containing syringes. The plasma was separated, and a saturated solution of ammonium sulfate was added at $4^{\circ} \mathrm{C}$ to yield a final concentration of $28 \%$. After $30 \mathrm{~min}$ the solution was centrifuged at $12,000 \mathrm{~g}$ for $10 \mathrm{~min}$. The resulting precipitate was discarded and the supernatant fluid made

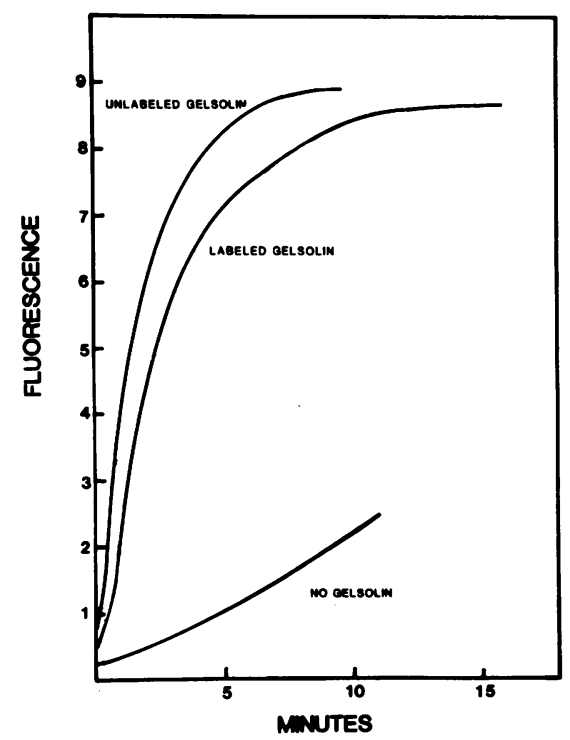

Figure 1. A functional assay of radiolabeled human plasma gelsolin. The polymerization rate of gelsolin-nucleated actin assembly was determined by adding labeled or unlabeled gelsolin to pyrene-actin (4 $\mu \mathrm{M})$ before the addition of $\mathrm{MgCl}_{2}$ (final concentration $2 \mathrm{mM}$ ) and $\mathrm{KCl}$ (final concentration $150 \mathrm{mM}$ ). The actin/gelsolin ratio was 70:1 and the $\mathrm{CaCl}_{2}$ concentration $0.2 \mathrm{mM}$. Addition of either labeled or unlabeled gelsolin to actin resulted in a rapid increase in the fluorescence of the pyrene-actin, indicating acceleration of its polymerization into filaments.
$50 \%$ with respect to a saturated solution of ammonium sulfate. After centrifugation, the precipitate formed was dissolved in 5-10 $\mathrm{ml}$ of PBS and dialyzed with frequent changes of the bath for $18 \mathrm{~h}$ against PBS. The dialysate was clarified by centrifugation and injected into fresh rabbits. Approximately $1 \mu \mathrm{g}$ of screened labeled gelsolin was injected into the second rabbit. Sodium dodecyl sulfate-polyacrylamide gel electrophoresis and autoradiography of an aliquot of the screened gelsolin preparation injected into the second rabbit revealed a single polypeptide that co-migrated with plasma gelsolin.

Ammonium sulfate precipitation is an integral step in the preparation of gelsolin as performed by many laboratories. In order to rule out the possibility that this maneuver damaged some proportion of the gelsolin molecules, the following experiment was performed. Human plasma was treated with ammonium sulfate in the same manner as the rabbit plasma containing the screened gelsolin. The precipitate from the 50\% ammonium sulfate cut was dissolved in and dialyzed against buffer B (buffer A with $0.15 \mathrm{M} \mathrm{KCl}$ and $2 \mathrm{mM} \mathrm{MgCl}$ ). The functional gelsolin activity of the treated plasma was the same as the untreated plasma with respect to both actin nucleation activity and actin filament-severing activity, indicating that the methods used to process the screened gelsolin did not harm the molecule.

Radiolabeled actin was added to solutions containing $25 \mathrm{mg}$ unlabeled actin under polymerizing conditions ( $2 \mathrm{mM} \mathrm{MgCl}_{2}$ and $\left.100 \mathrm{mM} \mathrm{KCl}\right)$. After allowing actin filaments to polymerize at $20^{\circ} \mathrm{C}$ for $2 \mathrm{~h}$, the solution was centrifuged for $4 \mathrm{~h}$ at $35,000 \mathrm{~g}$ at $4^{\circ} \mathrm{C}$. The actin filament pellet was washed and resuspended in $1 \mathrm{ml}$ of PBS. It was dialyzed against PBS with frequent changes of the dialysate for $24 \mathrm{~h}$. The solution was clarified by centrifugation at $12,000 \mathrm{~g}$ for $10 \mathrm{~min}$ at $4^{\circ} \mathrm{C}$ and injected into rabbits. $3 \mathrm{mg}$ of actin were injected into each rabbit.

Radiolabeled DBP was passed over an actin affinity column as described for the purification of the protein. The labeled DBP was eluted with $0.25 \mathrm{M}$ glycine, $\mathrm{pH} 2.75$. The $\mathrm{pH}$ was brought to 7.0 by adding $\mathrm{NaOH}$, and the protein was dialyzed overnight at $4^{\circ} \mathrm{C}$ against PBS, after which time it was injected into rabbits.

Radiolabeled fibronectin was added to $0.5 \mathrm{ml}$ of human serum and then passed over a $2.5-\mathrm{ml}$ gelatin-Sepharose column. After washing the column, the labeled fibronectin was eluted with $1 \mathrm{M}$ arginine, $\mathrm{pH} 5.5$, and dialyzed into a buffer containing $50 \mathrm{mM}$ Tris, $100 \mathrm{mM} \mathrm{NaCl}$, pH 7.4.

${ }^{125}$ I-actin-DBP complexes were prepared by mixing equimolar amounts of DBP (in PBS) and labeled actin (in buffer A). The final actin concentration was $20 \mu \mathrm{M}$ in $2 \mathrm{ml}$. The complexes were allowed to form at room temperature for $60 \mathrm{~min}$ before being injected into rabbits. 0.5 $\mu \mathrm{g}$ of actin was injected into each rabbit.

${ }^{125} \mathrm{I}$-actin-gelsolin complexes were formed by mixing radiolabeled actin (in buffer A with $2 \mathrm{mM} \mathrm{MgCl}$ and $100 \mathrm{mM} \mathrm{KCl}$ ) with plasma gelsolin (in PBS) at an actin/gelsolin molar ratio of 2:1 (final actin concentration, $20 \mu \mathrm{M}$ ). The mixtures were incubated for $60 \mathrm{~min}$ at room temperature. Since DBP removes one actin molecule from a 2:1 actin/ gelsolin complex (23), we incubated these complexes with DBP-Sepharose to make 1:1 actin/gelsolin complexes. The $2: 1$ complexes, in $1.2 \mathrm{ml}$, were added to $2 \mathrm{ml}$ of DBP-Sepharose beads $(1 \mathrm{mg} \mathrm{DBP} / \mathrm{ml}$ of Sepharose 4B) and rotated end-over-end for $1 \mathrm{~h}$ at room temperature. The mixture was centrifuged for $12,000 \mathrm{~g}$ for $5 \mathrm{~min}$ and the supernatant removed for injection into rabbits. Half of the actin molecules were removed from each 2:1 complex, as verified by counting the DBP-Sepharose beads, thereby producing 1:1 actin/gelsolin complexes.

Actin filaments that contained gelsolin at their fast-growing ends (gelsolin-actin complexes) were prepared by adding ${ }^{125} \mathrm{I}$-labeled human plasma gelsolin $(7 \mu \mathrm{g})$ to a solution containing G-actin $(5 \mathrm{mg})$ in the presence of $100 \mathrm{mM} \mathrm{KCl}$ and $2 \mathrm{mM} \mathrm{MgCl}_{2}$. Polymerization was allowed to proceed for $1 \mathrm{~h}$ at $20^{\circ} \mathrm{C} .1 \mathrm{M} \mathrm{MgCl}_{2}$ was then added to a final concentration of $0.05 \mathrm{M}$, which caused actin paracrystals to form (24). The paracrystals were collected by centrifugation at $45,000 \mathrm{~g}$ for $3 \mathrm{~h}$ at $4^{\circ} \mathrm{C}$. They were dialyzed against 4 liters of $\mathrm{PBS}$ with $2 \mathrm{mM} \mathrm{MgCl}_{2}$ and $1 \mathrm{mM}$ $\mathrm{CaCl}_{2}$ overnight, which solubilized the paracrystals. Magnesium-induced actin paracrystals were prepared as a way of separating gelsolin-actin complexes from nonfunctional gelsolin molecules. The precipitation of 
magnesium-induced actin paracrystals was undertaken to insure that only actin-binding molecules would be collected. The use of paracrystals rather than dispersed actin filaments increased the efficiency of collection, since complexes of gelsolin with short actin filaments may not pellet during centrifugation. The actin-gelsolin complexes were then injected into rabbits and the plasma decay curves determined as described below.

The following experiment was performed to show that gelsolin was not damaged by the magnesium, and that gelsolin-actin complexes are stable in $50 \mathrm{mM} \mathrm{Mg}^{2+}$. Human plasma gelsolin $(1 \mathrm{mg} / \mathrm{ml})$ was added to either buffer B or buffer B with F-actin $(2 \mathrm{mg} / \mathrm{ml})$. After incubation for 10 min at room temperature $\mathrm{MgCl}_{2}$ was added to a final concentration of $50 \mathrm{mM}$. After further incubation at room temperature for $1 \mathrm{~h}$, the solutions were dialyzed overnight at $4^{\circ} \mathrm{C}$ against buffer $\mathrm{B}$, and were then analyzed for functional gelsolin activity. Both the treated gelsolin and gelsolin-actin solutions nucleated actin filament assembly at the same rate as the untreated gelsolin. The treated gelsolin also severed actin filaments in an identical manner to the untreated gelsolin. The solution containing both actin and gelsolin did not sever actin filaments. Since gelsolin-actin complexes nucleate filament assembly but do not cut filaments, these findings indicate both that gelsolin retains its function and that gelsolin-actin complexes are present after exposure to $50 \mathrm{mM} \mathrm{Mg}^{2+}$.

\section{Fibronectin-binding experiments}

Radiolabeled fibronectin was incubated with F-actin in buffer A with 2 $\mathrm{mM} \mathrm{MgCl}$ and $100 \mathrm{mM} \mathrm{KCl}$ for $60 \mathrm{~min}$ at room temperature. The solutions were then centrifuged at $160,000 \mathrm{~g}$ for $60 \mathrm{~min}$ at room temperature in an airfuge. The supernatant was separated from the pellet. $100 \mu \mathrm{l}$ of the supernatant was taken for counting in a gamma counter. The pellet was washed once with polymerizing buffer and then counted.

\section{Effect of fibronectin on actin polymerization}

Fibronectin was added to pyrene-labeled G-actin and the polymerization of actin was monitored by a change in the fluorescence of the actin as previously described (5).

\section{Measurements of plasma gelsolin levels}

Levels of plasma gelsolin in humans and rabbits were measured by a functional assay that measures the ability of plasma gelsolin to nucleate actin filament assembly in a concentration-dependent fashion in the presence of calcium (Smith, D. B., P. A. Janmey, T. J. Herbert, and S. E. Lind, manuscript submitted for publication).

\section{Animal experiments}

Kinetic studies. New Zealand White rabbits $(3.0-3.5 \mathrm{~kg})$ were given free access to drinking water containing $0.02 \% \mathrm{NaI}$. Before the injection of radiolabeled proteins, $1 \mathrm{ml}$ of blood was drawn for measurement of baseline plasma gelsolin levels. The rabbits were injected with labeled proteins in $1 \mathrm{ml}$ of PBS via a marginal ear vein and were bled from the opposite ear.

$10 \mathrm{~min}$ after the protein was injected, $1 \mathrm{ml}$ of blood was drawn from the contralateral ear into a syringe containing $10 \mu \mathrm{l}$ of heparin $(10 \mathrm{U})$, and the plasma separated. $0.4 \mathrm{ml}$ of plasma was added to $2 \mathrm{ml}$ of icecold 10\% TCA and the radioactivity in the precipitates that formed was determined in a gamma counter. Blood samples were obtained at intervals thereafter and the plasma level of TCA-precipitable radioactivity at each time expressed as a percent of the counts present in the 10-min sample.

Organ clearance distribution studies. Rabbits were injected with TCgelsolin (50 $\mu \mathrm{g})$ or TC-actin (425 $\mu \mathrm{g})$ and blood was drawn for the determination of TCA-precipitable counts in the plasma as described above. At the indicated times, the animals were killed by intravenous injection of $350 \mathrm{mg}$ of sodium pentobarbital. The viscera were removed, washed in saline, blotted dry, and weighed. Samples of the organs ( $\sim 1 \mathrm{~g}$ each) were excised, blotted dry, weighed, and counted in a gamma counter.

Data analysis. The kinetic data was analyzed by the method of Matthews (25). The TCA-precipitable radioactivity remaining in the plasma was plotted against time on semilogarithmic graph paper. Curve peeling was used to determine the parameters of clearance, allowing calculation of the fractional catabolic rates in the standard fashion. The synthetic rate was calculated by the formula: synthetic rate $(\mathrm{mg} / \mathrm{kg}$ per $\mathrm{h})=\mathrm{C}$ $\times \mathrm{V} \times \mathrm{FCR} / \mathrm{W}$ where $\mathrm{C}$ is the plasma concentration of gelsolin (milligrams/milliliters), $\mathrm{V}$ the plasma volume (equal to the animals's weight in grams $\times 0.04$, expressed in milliliters), FCR the fractional catabolic rate and $W$ the animal's weight (kilograms).

The sites of clearance of labeled TC-gelsolin or TC-actin were determined by the method of Webster et al. (26). The parameter $R$, a measure of the clearance of the protein per mass of an organ, was calculated by the formula: $R=$ micrograms of gelsolin in the organ per gram of organ/micrograms of gelsolin injected per gram of total body weight. We developed a second parameter, $R^{\prime}$, multiplying $R$ by the organ weight to obtain a measure of the clearance of gelsolin by each organ, a value weighted by the total mass of each organ.

\section{Results}

Kinetics of plasma gelsolin. In some experiments, labeled human plasma gelsolin was screened in one rabbit before being injected into a second for the determination of its plasma kinetics (Fig. 2). The half-life of the terminal phase of the decay curve was $2.3 \mathrm{~d}$, similar to that found when unscreened gelsolin was injected directly. Other clearance parameters changed as a result of screening, as shown in Table I. Almost $50 \%$ of the total plasma gelsolin is extravascular.

Similar studies were carried out with rabbit plasma gelsolin. Rabbits were found to have higher plasma gelsolin levels than humans (mean of 8 rabbits $=368 \mu \mathrm{g} / \mathrm{ml}$, mean of 56 humans $=211 \mu \mathrm{g} / \mathrm{ml}$ ). Kinetic parameters comparable to those obtained for human plasma gelsolin were found as shown in Table I, although the fractional catabolic rate for screened rabbit plasma gelsolin was greater than that for the screened human protein $(0.059 \% / \mathrm{h}$ vs. $0.036 \% / \mathrm{h})$. The mean synthetic rate for plasma gelsolin for the three animals receiving rabbit plasma gelsolin was $0.65 \mathrm{mg} / \mathrm{kg}$ per $\mathrm{h}$.

Sites of clearance of plasma gelsolin. The clearance of TCgelsolin from the plasma was comparable to unconjugated gelsolin (data not shown). Four rabbits were studied with labeled TC-gelsolin. As shown in Table II, the liver is the main site of accumulation, and, presumably, degradation, of plasma gelsolin. The values presented reflect the total organ accumulation of the

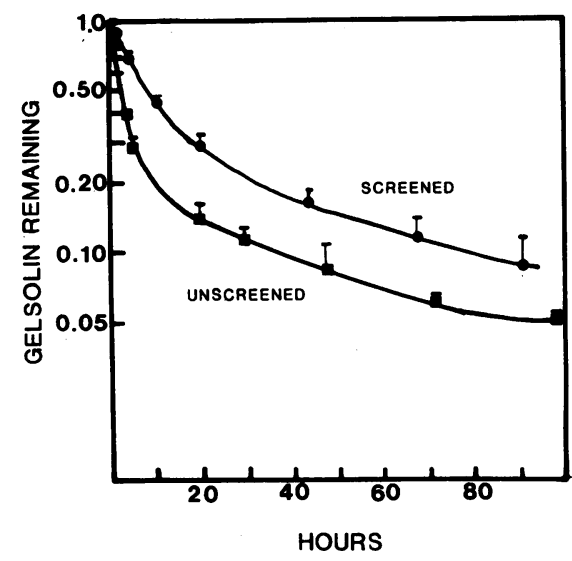

Figure 2. Kinetics of plasma clearance of radiolabeled human plasma gelsolin. Gelsolin was labeled with ${ }^{125} \mathrm{I}$ and injected into rabbits. Screened gelsolin was prepared by injecting gelsolin into a rabbit and then harvesting its plasma $3 \mathrm{~h}$ later. The gelsolin-containing ammonium sulfate fraction was injected into a second rabbit and the plasma decay curve determined. Three rabbits received unscreened gelsolin and four rabbits received screened gelsolin. 
Table I. Plasma Gelsolin Clearance Kinetics

\begin{tabular}{|c|c|c|c|c|}
\hline Gelsolin & $t_{1 / 2}$ & FCR & $\begin{array}{l}\mathrm{E} / \mathrm{P} \\
\text { ratio }\end{array}$ & Intravascular \\
\hline & $d$ & $h$ & & $\%$ \\
\hline Human, & 2.6 & 0.029 & 1.4 & 42 \\
\hline \multirow[t]{3}{*}{ Screened } & 1.9 & 0.038 & 1.1 & 47 \\
\hline & 2.2 & 0.037 & 1.2 & 45 \\
\hline & 1.8 & 0.040 & 1.0 & 50 \\
\hline Mean & 2.1 & 0.036 & 1.18 & 46 \\
\hline Rabbit, & 2.2 & 0.053 & 2.4 & 30 \\
\hline \multirow[t]{2}{*}{ Screened } & 2.7 & 0.053 & 2.8 & 26 \\
\hline & 2.1 & 0.072 & 2.9 & 26 \\
\hline Mean & 2.3 & 0.059 & 2.7 & 27 \\
\hline \multicolumn{5}{|l|}{ Human, } \\
\hline \multirow[t]{3}{*}{ Unscreened } & 2.4 & 0.064 & 3.5 & 22 \\
\hline & 2.7 & 0.053 & 3.3 & 23 \\
\hline & 2.1 & 0.069 & 3.0 & 25 \\
\hline Mean & 2.4 & 0.062 & 3.3 & \\
\hline \multicolumn{5}{|l|}{ Human, } \\
\hline $\mathrm{Mg}^{++}$-treated & 3.0 & 0.043 & 2.8 & 26 \\
\hline Unscreened & 3.3 & 0.041 & 3.1 & 24 \\
\hline
\end{tabular}

$\mathrm{E} / \mathrm{P}$, ratio of protein in the extravascular/intravascular space; FCR, fractional catabolic rate.

Each value represents a separate experiment performed on different days.

protein (including the vascular, cellular, and extracellular compartments), although the constancy of the values obtained for the solid organs suggests that the adduct has reached equilibrium with a cellular pool.

Clearance of actin from the circulation. Radiolabeled F-actin was injected into rabbits and the clearance of radioactivity from the circulation determined, as shown in Fig. 3. Actin was cleared from the circulation with a half-disappearance time of $\sim 30 \mathrm{~min}$ (G-actin was not injected since it rapidly binds preferentially to DBP, and would simply give a G-actin-DBP clearance curve. F-actin, on the other hand, interacts in a sequential and defined manner with both gelsolin and DBP [23].)

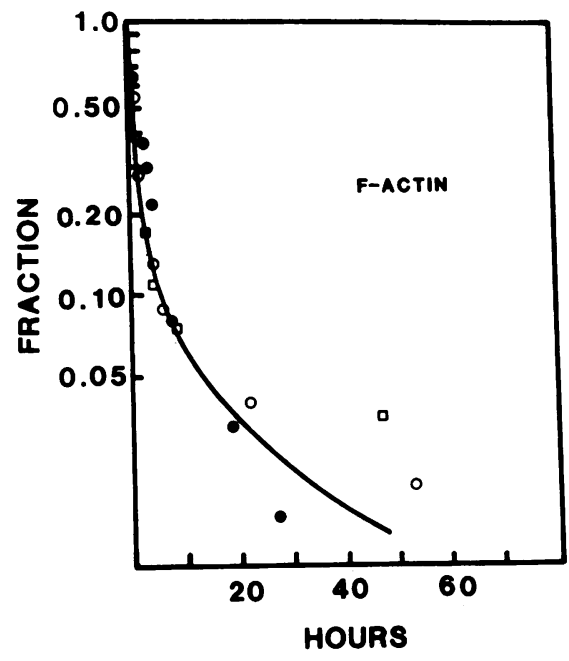

Figure 3. Kinetics of clearance of F-actin. ${ }^{125} \mathrm{I}$-actin was prepared and polymerized into filaments with unlabeled actin. The actin was injected into rabbits and the decay of TCA-precipitable radioactivity in the plasma determined. The different symbols represent separate animals studied.

The clearance of the ${ }^{125} \mathrm{I}$-TC-actin from the circulation was similar to that seen when ${ }^{125} \mathrm{I}$-actin was injected (data not shown). Table III indicates that while the lung and spleen may play a role in actin clearance, the liver is the major site of clearance of ${ }^{125} \mathrm{I}$-TC-actin. The decline in whole organ accumulation by the lung and spleen with the passage of time may be due to the fact that these data reflect labeled species in both the cellular and extracellular compartments, as discussed above. Similar results were found when the organs of animals that had received ${ }^{125} \mathrm{I}$ actin were excised and counted.

The effect of actin on the clearance of gelsolin from the plasma. In order to determine whether actin affects the clearance of gelsolin, complexes of radiolabeled gelsolin and unlabeled actin were prepared in vitro and injected into rabbits. As shown in Fig. 4, the actin-gelsolin complexes were cleared from the plasma more rapidly than either screened or unscreened gelsolin. Since magnesium-induced paracrystal formation was used to prepare these complexes, unscreened gelsolin alone was treated with

Table II. Organ Clearance of Plasma Gelsolin

\begin{tabular}{|c|c|c|c|c|c|c|c|c|}
\hline & \multicolumn{8}{|c|}{ Rabbit } \\
\hline & $\mathrm{A}^{*}$ & & $\mathrm{~B}^{*}$ & & $\mathrm{C}^{*}$ & & $D^{*}$ & \\
\hline & $R$ & $\left(R^{\prime}\right)$ & $R$ & $\left(R^{\prime}\right)$ & $R$ & $\left(R^{\prime}\right)$ & $R$ & $\left(R^{\prime}\right)$ \\
\hline Liver & 4.3 & $(360)$ & 4.9 & (394) & 3.3 & (290) & 4.0 & (388) \\
\hline Kidney & 1.5 & (26) & 1.8 & (25) & 0.9 & (13) & 1.1 & (20) \\
\hline Spleen & 0.7 & $(0.9)$ & 0.8 & $(0.8)$ & - & & 0.4 & $(0.9)$ \\
\hline Lungs & 0.6 & & 0.2 & & 0.1 & $(0.4)$ & 0.1 & (1.3) \\
\hline Heart & 0.2 & $(1.0$ & 0.2 & (1.4) & 0.1 & $(0.8)$ & 0.1 & $(0.6)$ \\
\hline Blood & 5.3 & & 0.4 & & 0.2 & & 0.2 & \\
\hline Muscle & 0.02 & & 0.1 & & 0.01 & & 0.01 & \\
\hline
\end{tabular}

$R$, micrograms of gelsolin in the organ per gram of organ/micrograms of gelsolin injected per gram of total body weight. $R^{\prime}, R \times$ organ weight.

* Time of death: A, $2 \mathrm{~h} ; \mathrm{B}, 24 \mathrm{~h} ; \mathrm{C}, 48 \mathrm{~h}$; and D, $48 \mathrm{~h}$. 
Table III. Organ Clearance of F-Actin

\begin{tabular}{lclllll}
\hline & Rabbit & & & & & \\
\cline { 2 - 7 } & $\mathrm{O}^{*}$ & & $\mathrm{P}^{*}$ & & $\mathrm{Q}^{*}$ & \\
\hline & $R$ & $\left(R^{\prime}\right)$ & $R$ & $\left(R^{\prime}\right)$ & $R$ & $\left(R^{\prime}\right)$ \\
Liver & 22 & $(1971)$ & 17 & $(2063)$ & 15 & $(2219)$ \\
Kidney & 6.5 & $(93)$ & 5 & $(97)$ & 4.8 & $(89)$ \\
Lung & 26 & $(192)$ & 23 & $(225)$ & 3.9 & $(38)$ \\
Spleen & 32 & $(32)$ & 27 & $(59)$ & 23 & $(11)$ \\
Heart & 0.7 & $(3.4)$ & 0.8 & $(5)$ & 0.9 & $(6)$ \\
Muscle & 0.2 & & 0.1 & & 0.1 & \\
Blood & 2 & & 0.34 & & 0.22 & \\
& & & & & & \\
\hline
\end{tabular}

$\boldsymbol{R}$, micrograms of gelsolin in the organ per gram of organ/micrograms of gelsolin injected per gram of total body weight. $R^{\prime}, R \times$ organ weight.

* Time of death: $0,3 \mathrm{~h} ; \mathrm{P}, 31 \mathrm{~h}$; and Q, $54 \mathrm{~h}$.

magnesium in an identical manner before being injected into rabbits to control for magnesium-mediated damage to the labeled gelsolin. The clearance of the magnesium-treated gelsolin was identical to that of unscreened gelsolin. Furthermore, magnesium treatment of unlabeled gelsolin did not affect its activity in vitro (see Methods). Since the clearance of this preparation was not faster than the clearance of actin alone, it is unlikely that damage to the actin by magnesium was responsible for the accelerated clearance of gelsolin.

The effect of actin on the clearance of DBP from the plasma. The clearance of ${ }^{125} \mathrm{I}-\mathrm{DBP}-\mathrm{G}$-actin complexes formed in vitro from the circulation of rabbits was more rapid than the clearance of uncomplexed ${ }^{125} \mathrm{I}-\mathrm{DBP}$, indicating that actin also accelerates the clearance of DBP from the plasma (Fig. 5).

Evidence that $D B P$ mediates the clearance of actin from the circulation. Having found that the clearance of both gelsolin and DBP was accelerated by actin, we performed a clearance study to determine which protein was likely to be responsible for the rapid clearance of actin from the circulation. ${ }^{125}$ I-actin-gelsolin and ${ }^{125} \mathrm{I}$-actin-DBP complexes were prepared and injected into rabbits. As shown in Fig. 6, the actin-DBP complexes were cleared more rapidly from the circulation than were the gelsolinactin complexes. Since the clearance of the gelsolin-actin complexes was slower than the clearance of the F-actin (Fig. 3), we

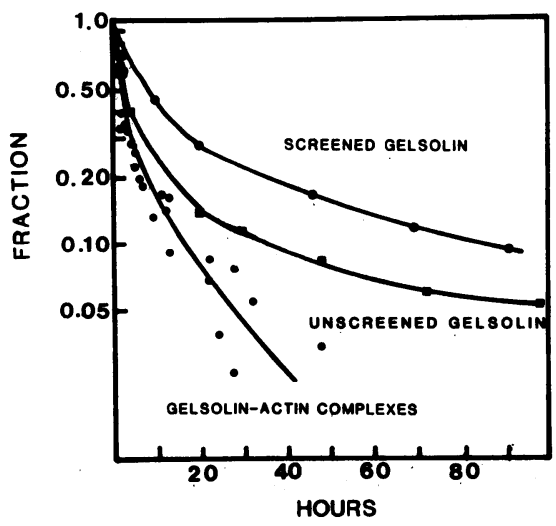

Figure 4. Accelerated clearance of gelsolin-actin complexes. Complexes of radiolabeled human plasma gelsolin and actin were injected into three rabbits and the clearance of the labeled gelsolin determined. Shown for comparison is the clearance of both screened and unscreened human plasma gelsolin.

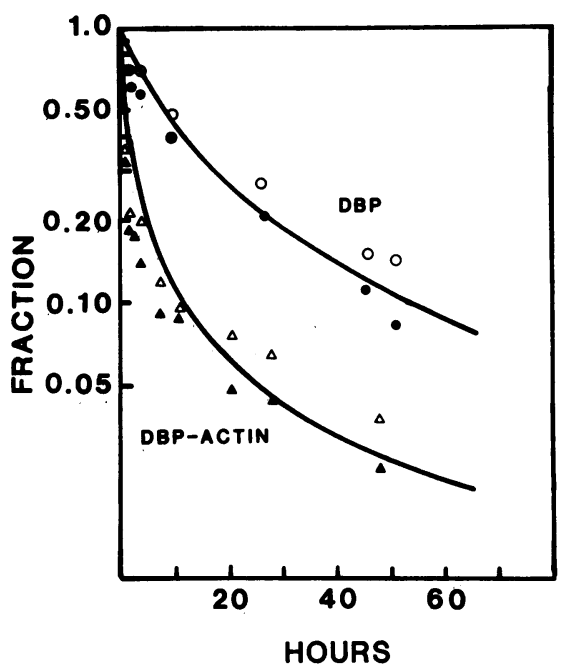

Figure 5. Accelerated clearance of DBP-actin complexes. Complexes of radiolabeled DBP and actin were prepared and injected into rabbits. The clearance of DBP alone is shown for comparison. The different symbols represent separate animals studied.

concluded that plasma gelsolin is probably important in shortening actin filaments in the circulation, but it is not the major plasma protein mediating the clearance of actin.

Interaction of actin with fibronectin. In the first set of experiments, fibronectin was added $(1.1 \mu \mathrm{M})$ to solutions of pyrenelabeled G-actin $(7.5 \mu \mathrm{M})$ before the addition of $\mathrm{K}^{+}$and $\mathrm{Mg}^{++}$ (final concentrations $0.15 \mathrm{M}$ and $1 \mathrm{mM}$, respectively) to induce polymerization. No effect was seen on the lag period before polymerization, or on the final extent of polymerization (data not shown).

In the second set of experiments, a quantitative assessment of the binding of fibronectin to F-actin was made. We were able to show an interaction between actin and fibronectin as reported by others, but found it to be of low affinity. The low affinity of the binding prevented us from attaining saturation and thus the

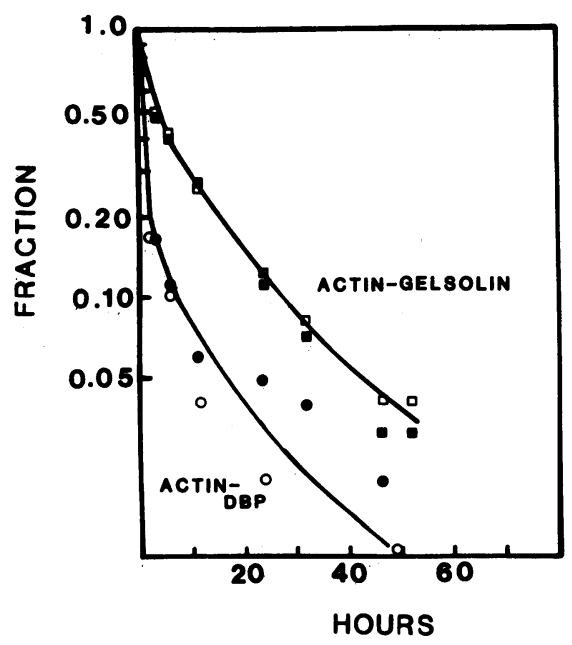

Figure 6. Clearance of actin-containing complexes from the plasma. Radiolabeled actin was used to prepare 1:1 complexes with either DBP or plasma gelsolin. The complexes were injected into separate rabbits in order to determine which ligand had a greater effect upon the clearance of actin from the plasma. The different symbols represent separate animals studied. 
affinity constant could not be obtained by a Scatchard analysis. We estimate the affinity of the actin-fibronectin interaction to be $2.9 \times 10^{-4} \mathrm{M}$ (data not shown).

\section{Discussion}

The disposition of actin, the major protein constituent of almost all nucleated mammalian cells, is of physiologic importance. It is likely that actin is present, at least transiently, in the extracellular space, as are a number of other cellular proteins. We therefore defined the clearance of actin from the circulation, and its effects upon the plasma kinetics of the two major circulating actin-binding proteins, DBP and plasma gelsolin.

Since the clearance of plasma gelsolin was not previously known, we determined its plasma kinetics. We found that actin accelerated the clearance of both DBP and plasma gelsolin from the circulation. Comparative studies using a single preparation of labeled actin indicated that DBP plays a more important role in clearing actin from the circulation than does plasma gelsolin.

Implicit in the plasma clearance studies is the assumption that the labeled species is not altered during the purification and labeling procedures. Frequently, a proportion of the molecules in question are damaged during preparation (27). We found this to be the case with labeled plasma gelsolin, as evidenced by the different metabolic parameters obtained when the labeled species was screened in one animal before being administered to another (Table I). If the screened molecule is isolated from the plasma, one risks damaging or losing a proportion of the labeled molecules. The route we followed, administering a plasma fraction that contained the labeled gelsolin, avoided this problem but resulted in the administration of unlabeled gelsolin as well. Our calculations are therefore based on the assumption that the clearance of gelsolin is independent of the plasma gelsolin level. While the integrity of the labeled species circulating in the animals was not examined during the course of the experiments, we have not observed fragmentation of gelsolin, actin, or DBP in other work we have performed.

Although screening is helpful in performing metabolic studies, it is not always feasible. In such cases we used other techniques to select for functional integrity in an effort to remove damaged species. It is possible that these procedures do not select for the same molecules, a reservation that must be kept in mind in considering our results.

Because of the large amount of unlabeled gelsolin administered with the screened material, we were not able to add enough actin to saturate the mixture of labeled and unlabeled gelsolin. We therefore developed a method of preparing gelsolinactin complexes that allowed us to simultaneously separate functional from nonfunctional gelsolin molecules. In using actin paracrystals to concentrate gelsolin we removed those radiolabeled gelsolin molecules that were not functionally intact and able to bind to actin. Thus, we made efforts through both the preparation of paracrystals and the screening maneuvers to remove damaged gelsolin molecules. It is possible, however, that the populations removed were not identical.

Affinity chromatography may also be used to separate molecules damaged during preparation and labeling (28), and we used this technique in the preparation of the labeled fibronectin and DBP. Actin molecules damaged during the labeling procedure were removed by polymerizing the functional labeled actin population with unlabeled actin, and sedimenting the polymerized actin.
Several plasma proteins other than plasma gelsolin and DBP have been reported to interact with actin, including: IgG (29), Clq (30), fibrin $(31,32)$, and plasma fibronectin $(33,34)$. The interaction of actin with plasma proteins other than fibrin has not been examined quantitatively, though it has been suggested that actin may interact with fibronectin at sites of tissue injury (35).

We examined the binding of fibronectin to actin, since it has been suggested that fibronectin binds weakly to actin under conditions of low ionic strength (34). We found that the affinity of fibronectin for actin was very low $\left(\sim 2.9 \times 10^{-4} \mathrm{M}\right)$. Since the affinity of actin for plasma gelsolin and DBP is orders of magnitude greater, we conclude that actin will not bind to fibronectin in the circulation in the face of adequate levels of DBP and plasma gelsolin.

A number of studies suggest that actin exists in two pools within cells, present either in a monomeric or polymeric form (36). Cell senescence or disruption of cells due to tissue injury would be expected to release both monomers (either free or bound to monomer-binding proteins, such as profilin) and filaments into the extracellular space. Since the ionic conditions needed to maintain actin filaments are present in plasma, actin filaments would be stable in plasma, and free monomers would be expected to polymerize or add to preexisting filament ends.

Several factors might work against the accumulation of long actin filaments in the vascular space: $(a)$ shear forces present in the circulation; $(b)$ dilution of the actin concentration to a level below the point where there is net depolymerization of filaments (the critical monomer concentration); and (c) depolymerization of filaments by plasma proteins. The first two factors are less likely to play a role in shortening actin filaments in the extracellular space contiguous to sites of tissue injury than they are in the circulation, especially where flow is rapid and turbulent. The existence of two actin depolymerizing proteins in the blood, present in micromolar concentrations, suggests that the body has a need to prevent long actin filaments from circulating.

Actin filaments in the extracellular space might alter some of the local properties of the microenvironment. For example, long filaments could increase the viscosity of the extracellular fluid, potentially affecting the normal traffic of cells and proteins into lymph. Alternatively, actin might interfere with other processes that occur in this compartment, such as clot formation. We have shown that actin filaments can affect the formation of a coarse fibrin clot by interfering with the lateral association of protofibrils into fibrin bundles. The addition of plasma gelsolin abrogates this effect by shortening actin filaments (32), indicating that for some processes, the state of actin assembly may be more important than the mere presence of actin.

Plasma gelsolin therefore appears to be important in severing actin filaments, and to play a secondary role in clearing actin monomers from the blood. The higher affinity of DBP for actin monomers indicates that plasma gelsolin will be left unbound if only a large amount of G-actin is released from cells (23). The DBP-actin complexes entering the circulation would be cleared quickly. The uncomplexed plasma gelsolin would then be free to sever actin filaments. These filaments might be released into the extracellular space, or found within dying cells where gelsolin can mediate the disassembly of the cytoskeleton (37). Higher levels of DBP (6-10 $\mu \mathrm{M})$ as compared with plasma gelsolin (1$3 \mu \mathrm{M})$ may be present to provide a high level of monomerbinding protein, thereby ensuring the presence of a maximal amount of free plasma gelsolin, which is capable of severing filaments. 
These studies suggest that there is a system in plasma designed to depolymerize and clear actin from the circulation. The combination of plasma gelsolin and DBP appears to be organized in a way that allows for the rapid clearance of actin while maximizing the ability of plasma gelsolin to depolymerize actin filaments.

\section{Acknowledgments}

The authors thank Ms. Toni-Junell Herbert for her technical assistance, Dr. Helen Yin for her gift of plasma gelsolin, and Dr. Christine Chaponnier for providing antigelsolin antibodies.

These studies were supported by grants HL-06749, HL-23591, AM35750, HL-19429, and HL-01063 from the National Institutes of Health.

\section{References}

1. Stossel, T. P. 1978. Contractile proteins in cell structure and function. Annu. Rev. Med. 29:427-457.

2. Harris, D. A., and J. H. Schwartz. 1981. Characterization of brevin, a serum protein that shortens actin filaments. Proc. Natl. Acad. Sci. USA. 78:6798-6802.

3. Chaponnier, C., R. Borgia, E. Rungger-Brandle, R. Weil, and G. Gabbiani. 1979. An actin-destabilizing factor is present in human plasma. Experientia (Basel). 35:1039-1041.

4. Norberg, R., R. Thorstensson, and A. Fagraeus. 1979. F-actindepolymerizing activity of human serum. Eur. J. Biochem. 100:575583.

5. Janmey, P. A., C. Chaponnier, S. E. Lind, K. S. Zaner, T. P. Stossel, and H. L. Yin. 1985. Interactions of gelsolin and gelsolin-actin complexes with actin. Effects of calcium on actin nucleation, filament severing and end blocking. Biochemistry. 24:3714-3723.

6. Van Baelen, H., R. Bouillon, and P. De Moor. 1980. Vitamin Dbinding protein (Gc-globulin) binds actin. J. Biol. Chem. 255:2270-2272.

7. Haddad, J. G. 1982. Human serum binding protein for vitamin D and its metabolites (DBP): evidence that actin is the DBP binding component in human skeletal muscle. Arch. Biochem. Biophys. 213: 538-544.

8. Thorstensson, R., G. Utter, and R. Norberg. 1982. Further characterization of the $\mathrm{Ca}^{2+}$-dependent $\mathrm{F}$-actin-depolymerizing protein of human serum. Eur. J. Biochem. 126:11-16.

9. Emerson, D. L., P. Arnaud, and R. M. Galbraith. 1983. Evidence of increased Gc:actin complexes in pregnant serum: a possible result of trophoblast embolism. AJIRI (Am. J. Reprod. Immunol.). 4:185-189.

10. Lee, W. M., D. L. Emerson, P. A. Werner, P. Arnaud, P. Goldschmidt-Clermont, and R. M. Galbraith. 1985. Decreased serum groupspecific component protein levels and complexes with actin in fulminant hepatic necrosis. Hepatology (Baltimore). 5:271-275.

11. Chaponnier, C., L. Kohler, and G. Gabbiani. 1977. Fixation of human anti-actin autoantibodies on skeletal muscle fibres. Clin. Exp. Immunol. 27:278-284.

12. De Scheerder, I., J. Vandekerckhove, J. Robbrecht, L. Algoed, M. DeBuyzere, J. DeLanghe, G. DeScrijver, and D. Clement. 1985. Postcardiac injury syndrome and an increased humoral immune response against the major contractile proteins (actin and myosin). Am. J. Cardiol. 56:631-633.

13. Haddad, J. G., D. R. Fraser, and D. E. M. Lawson. 1981. Vitamin $D$ plasma binding protein. Turnover and fate in the rabbit. J. Clin. Invest. 67:1550-1560.

14. Yin, H. L., D. J. Kwiatkowski, J. E. Mole, and F. S. Cole. 1984. Structure and biosynthesis of cytoplasmic and secreted variants of gelsolin. J. Biol. Chem. 259:5271-5276.

15. Haddad, J. G., M. A. Kowalski, and J. W. Sanger. 1984. Actin affinity chromatography in the purification of human, avian and other mammalian plasma proteins binding vitamin $\mathrm{D}$ and its metabolites $(\mathrm{Gc}$ globulins). Biochem. J. 218:805-810.

16. Chaponnier, C., and H. L. Yin. 1984. Monoclonal antibodies against cytoplasmic and plasma gelsolin. J. Cell Biol. 99:307a. (Abstr.)

17. Vuento, M., and A. Vaheri. 1979. Purification of fibronectin from human plasma by affinity chromatography under non-denaturing conditions. Biochem. J. 183:331-337.

18. Spudich, J. A., and S. Watt. 1971. The regulation of rabbit skeletal muscle contraction. J. Biol. Chem. 245:4866-4871.

19. Kouyama, T., and K. Mihashi. 1981. Fluorimetry study of N(1-pyrenyl)iodoacetamide-labelled F-actin. Local structural change of actin protomer both on polymerization and on binding of heavy meromyosin. Eur. J. Biochem. 114:33-38.

20. Lind, S. E., and P. A. Janmey. 1984. Human plasma gelsolin binds to fibronectin. J. Biol. Chem. 259:13262-13266.

21. Pittman, R. C., T. E. Carew, C. K. Glass, S. R. Green, C. A. Taylor, and A. D. Attie. 1983. A radioiodinated, intracellularly trapped ligand for determining the sites of plasma protein degradation in vivo. Biochem. J. 212:791-800.

22. Glass, C. K., R. C. Pittman, G. A. Keller, and D. Steinberg. 1983. Tissue sites of degradation of apoprotein A-I in the rat. J. Biol. Chem. 258:7161-7167.

23. Janmey, P. A., T. P. Stossel, and S. E. Lind. 1986. Sequential binding of actin monomers to plasma gelsolin and its inhibition by vitamin D-binding protein. Biochem. Biophys. Res. Commun. 136:72-79.

24. Kawamura, M., and K. Maruyama. 1970. Electron microscopic particle length of F-actin polymerized in vitro. J. Biochem. (Tokyo). 68: 885-899.

25. Matthews, C. M. E. 1957. The theory of tracer experiments with ${ }^{131}$ I-labelled plasma proteins. Phys. Med. Biol. 2:36-53.

26. Webster, R. O., G. L. Larsen, and P. M. Henson. 1982. In vivo clearance and tissue distribution of C5a and C5a des arginine complement fragments in rabbits. J. Clin. Invest. 70:1177-1183.

27. Osborne, J. C., E. J. Schaefer, G. M. Powell, N. S. Lee, and L. A. Zech. 1984. Molecular properties of radioiodinated apolipoprotein A-I. J. Biol. Chem. 259:347-353.

28. Carlson, T. H., A. C. Atencio, and T. L. Simon. 1984. In vivo behavior of radioiodinated rabbit antithrombin III. Demonstration of a noncirculating vascular compartment. J. Clin. Invest. 74:191-199.

29. Fecheimer, M., J. L. Daiss, and J. J. Cebra. 1979. Interaction of immunoglobulin with actin. Mol. Immunol. 16:881-888.

30. Nishioka, M., K. Kobayashi, M. Uchida, and T. Nakamura. 1982. A binding activity of actin with human Clq. Biochem. Biophys. Res. Commun. 108:1307-1312.

31. Laki, K., and L. Muszbek. 1974. On the interaction of F-actin with fibrin. Biochim. Biophys. Acta. 371:519-525.

32. Janmey, P. A., S. E. Lind, H. L. Yin, and T. P. Stossel. 1985. Effects of semi-dilute actin solutions on the mobility of fibrin protofibrils during clot formation. Biochim. Biophys. Acta. 841:151-158.

33. Keski-Oja, J., A. Sen, and G. J. Todaro. 1980. Direct association of fibronectin and actin molecules in vitro. J. Cell Biol. 85:527-533. '

34. Koteliansky, V. E., M. A. Glukhova, A. D. Morozkin, A. P. Musatov, V. P. Shirinsky, L. A. Tshovrebova, and V. N. Smirnov. 1981. A study of actin-fibronectin interaction. FEBS (Fed. Eur. Biochem. Soc.) Lett. 133:31-35.

35. Dillon, B. C., J. E. Estes, T. M. Saba, F. A. Blumenstock, E. Cho, S. K. Lee, and E. P. Lewis. 1983. Actin-induced reticuloendothelial phagocytic depression as mediated by its interaction with fibronectin. Exp. Mol. Pathol. 38:208-223.

36. Stossel, T. P. 1984. Contribution of actin to the structure of the cytoplasmic matrix. J. Cell Biol. 99:15s-21s.

37. Chaponnier, C., P. Patebex, and G. Gabbiani. 1985. Human plasma actin-depolymerizing factor. Purification, biological activity and localization in leukocytes and platelets. Eur. J. Biochem. 146:267-276. 